Article

\title{
Farmers' Perceptions, Insight Behavior and Communication Strategies for Rice Straw and Stubble Management in Thailand
}

\author{
Sukanya Sereenonchai * and Noppol Arunrat
}

check for

updates

Citation: Sereenonchai, S.; Arunrat,

N. Farmers' Perceptions, Insight

Behavior and Communication

Strategies for Rice Straw and Stubble

Management in Thailand. Agronomy

2022, 12, 200. https://doi.org/

10.3390/agronomy12010200

Academic Editors: Moritz Von Cossel Joaquín Castro-Montoya and Yasir Iqbal

Received: 3 December 2021

Accepted: 12 January 2022

Published: 14 January 2022

Publisher's Note: MDPI stays neutral with regard to jurisdictional claims in published maps and institutional affiliations.

Copyright: (C) 2022 by the authors. Licensee MDPI, Basel, Switzerland. This article is an open access article distributed under the terms and conditions of the Creative Commons Attribution (CC BY) license (https:// creativecommons.org/licenses/by/ $4.0 /$ )
Faculty of Environment and Resource Studies, Mahidol University, Salaya, Nakhon Pathom 73170, Thailand; noppol.aru@mahidol.ac.th

* Correspondence: sukanya.ser@mahidol.ac.th

\begin{abstract}
The adoption of rice straw and stubble management approaches can be affected by various factors. To understand the psychological factors influencing Thai farmers' adoption of rice straw and stubble management approaches, three integrated behavioral theories were employed: the Theory of Planned Behavior (TPB), the Value-Belief-Norm (VBN) and the Health Belief Model (HBM). Then, a practical communication framework was synthesized and proposed to promote rice straw utilization for social-ecological benefits to achieve more sustainable agricultural production. Through a questionnaire survey and in-depth interviews with 240 local farmers, a statistical analysis was performed employing cross-tab, stepwise multiple linear regression, one-way ANOVA and descriptive content analysis using QDA lite miner software. The key results clearly showed that perceived pro-environmental personal norms, perceived cues to rice straw utilization, perceived behavioral control, perceived severity of rice straw burning, perceived ascription of responsibility, and the perceived benefits of rice straw utilization were significantly negatively influenced by burning, and that there was a significantly negative difference to non-burning approaches. Meanwhile, cost savings as perceived benefits of the current option of burning showed a significantly positive difference when compared with incorporation and free-duck grazing options. In communication strategies to promote rice straw utilization for achieving sustainable agriculture, key messages should highlight the clear steps of rice straw utilization, as well as the costs and benefits of each option in terms of economic, health, environmental and social perspectives. Moreover, messages designed to promote action knowledge and self-efficacy at the group level, to promote perceived responsibility via self-awareness and self-commitment, and convenient channels of communication to the farmers can help to achieve more effective non-burning rice straw and stubble management.
\end{abstract}

Keywords: farmers' perceptions; insight behavior; communication strategies; rice straw and stubble management; sustainable agricultural production; Thailand

\section{Introduction}

The open-field burning of rice straw and stubble is a common practice in many countries. Recently, burning has caused serious air pollution problems worldwide [1], which has resulted in calls for participation from stakeholders to deal with this issue. Air pollution from open burning has also been a serious environmental health risk impacting Thai people [2]. The air pollutants from crop residues due to open burning in Thailand were found to be primarily $\mathrm{CO}_{2}, \mathrm{CO}, \mathrm{PM}_{10}, \mathrm{PM}_{2.5}$ [3].

In Thailand, the Department of Agricultural Extension has recognized the importance of this problem. Therefore, a project to promote the cessation of burning in agricultural areas was initiated in 2014 and continues to this day, which aims to expand the results across the country [4]. Although some technologies have been introduced to Thai society as options to avoid burning and to benefit from the use of rice straw through compacting, soil covering, incorporation, growing mushrooms, etc., the problem of open-field burning remains a serious issue. In practice, however, many farmers still burn rice straw and stubble. 
The relevant authorities have not yet been able to take legal action. Therefore, questions arise as to why farmers choose to burn rice straw and stubble, and which management options are the most cost-effective for farmers and society at large.

Based on a literature review, some previous studies employed behavioral theories to understand farmers' climate mitigation and adaptation behaviors (e.g., [5-8]). To the best of our knowledge, one study used the Theory of Planned Behavior (TPB) to investigate the factors and mechanisms driving the straw resource utilization behaviors of Chinese farmers [9]. Meanwhile, other relevant studies were more focused on using quantitative analysis to explore the factors influencing rice straw management practices $[1,10]$ that were not directly based on behavioral theory. There was still a research gap in applying behavioural theory to understand farmers' behaviors especially regarding rice straw management, and the lack of practical communication strategies to promote non-burning approaches.

Consequently, the present study took both qualitative and quantitative approaches aiming to answer two main questions: (1) What are the key psychological factors influencing farmers' decisions to adopt each type of rice straw and stubble management; (2) What communication strategies should be planned and practiced further for promoting nonburning rice straw and stubble management approaches? The contribution of this study could promote rice straw utilization for social-ecological benefits for the achievement of more sustainable agricultural production.

\section{Literature Review on Factors Influencing Farmers' Rice Straw Management Practice}

\subsection{Application of the TPB, VBN and HBM to Understand Farmers' Decision}

This study utilized three integrated behavioral theories (Figure 1) consisting of the Theory of Planned Behavior (TPB), the Value-Belief-Norm (VBN) and the Health Belief Model (HBM), which were proposed by Zhang et al. [6], Abdollahzadeh and Sharifzadeh [7] and Ataei et al. [8], respectively, to understand the psychological factors influencing farmers' adoption of each rice straw and stubble management approach.

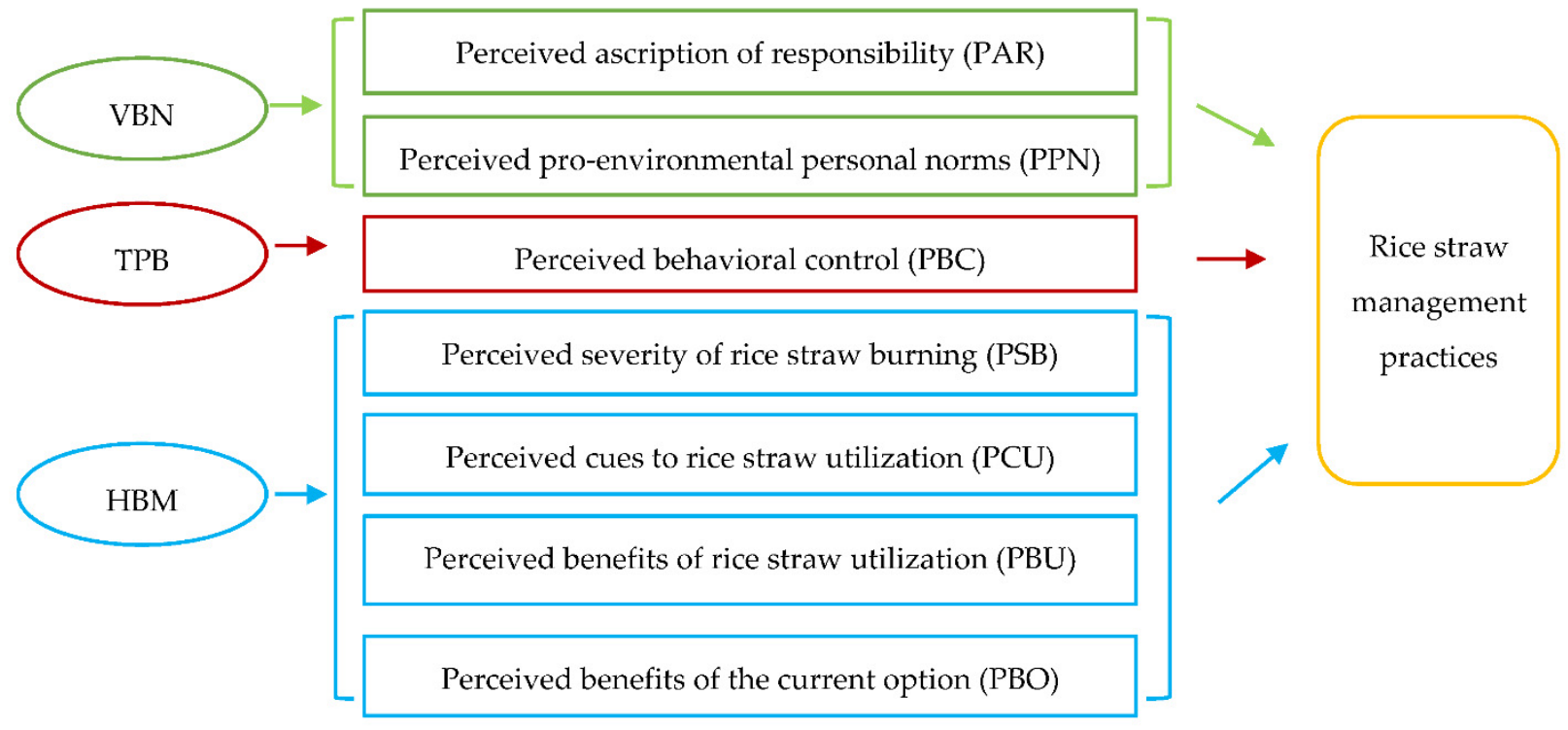

Figure 1. Integrated theories of TPB, VBN and HBM using in this study.

Based on the TPB, behavioral intention is influenced by attitude, subjective norms, and perceived behavioral control [11-13]. The Value-Belief-Norm (VBN) theory moves from personal values (biospheric, altruistic, and egoistic values) to the new environmental paradigm, which includes an awareness of consequences, the ascription of responsibility, and proenvironmental personal norms, and finally leads to pro-environmental behaviors [14].

The TPB and VBN models were employed to predict Chinese farmers' intentions in relation to farmers' climate mitigation and adaptation behaviors using partial least squares 
structural equation modelling (PLS-SEM) [6]. The TPB was found to be more successful for predicting self-interest-oriented behaviors like climate adaptation, while the VBN theory better explained altruistic behaviors like climate mitigation. The TPB and HBM models were also employed together to explore farmers' intentions to use green pesticides based on Structural equation modelling (SEM) for data analysis. Key results highlighted that both theories could predict the intention, while HBM was better than TPB [8]. Furthermore, the HBM was particularly applied with respect to health-issue relevance. One example employed the HBM to examine the factors affecting farmers' intentions to use personal protective equipment (PPE), three components were positively found: higher levels of perceived severity of pesticide adverse effects; cues to action; and perceived PPE benefits [7].

To understand health-related behaviors, the HBM has been claimed by some scholars to be the most appropriate and widely employed framework. The model consisted of perceived severity, perceived susceptibility, perceived barriers, perceived benefits, perceived self-efficacy, and cues to action [15]. The HBM was applied with some studies regarding farmers' behaviors such as farmers' intentions and safety behavior regarding pesticides $[7,16,17]$. For rice straw management options, there is also a health-related issue because the burning method can also generate air pollution. Therefore, this study also integrated the HBM to understand farmers' decisions with respect to their concern over people's health.

\subsection{Factors Influencing Farmers' Decision to Choose Rice Straw Management Practices \\ 2.2.1. Factors Influencing Burning Decision}

Based on the logit regression model, which is used to understand why the Indian farmers choose each crop residue practice, social influence was found as a significant determinant of residue burning [18]. Additionally, weather (humidity and rain), disproportionate incentives, inefficient straw collection technology, inefficient management from agricultural agencies, lack of logistic facilities (baler machines, storage and transportation), lack of capital to manage straw, and a low level of skills and knowledge were found for Malaysian farmers, where farmers also realized the benefits of rice straw burning due to it having no serious impacts, and being the easier and cheaper option [10]. Although the farmers perceived high risks, few benefits, low acceptance for rice straw burning [10], and an awareness of its adverse environmental effects [18], they retained their burning practice $[10,18]$.

\subsubsection{Factors Influencing Non-Burning Decision}

To analyze the factors influencing farmers' adoption of different rice straw management techniques, i.e., covering, burning, incorporation, or rice straw removal using multinomial logit models [1], farm type, location, number of household members, cow ownership, and distance from farm to house, were found to significantly influence farmers' use of alternative techniques, i.e., incorporation or removal instead of burning. Other factors that also influenced farmers to incorporate alternative techniques instead of burning were training attendance, perceptions of incorporation benefits, income from non-rice farming, cultivated area, tenure status, and provincial regulations of burning. Moreover, the significant perception variables for Vietnamese farmers to incorporate were the negative impacts of open-field burning, awareness of environmental regulations, and attitude towards incentives. They adopted and incorporated these perception variables for themselves rather than for the environment or society [10].

These attitudes were also mentioned by Kadam et al. [19] as the most important for changing straw management practices in the United States, particularly regulation with greater economic incentives for cooperation with rice straw collection advice, which might help to change farmers' attitudes. The economic or financial incentive could be a powerful driver for farmers to choose a non-burning approach $[10,20,21]$. In addition, to investigate the impact of policy measures on Chinese farmers' rice straw management using a regression model, key results highlighted that the burning ban has reduced rice 
straw burning dramatically and motivated farmers to retain straw in their soil. However, the straw retention subsidy seemed to have an insignificant effect because it was low and not directly provided to farmers [22].

In order to promote non-burning and more sustainable farming practices, acceptability, feasibility and benefit perception should be promoted $[10,23]$.

\section{Materials and Methods}

\subsection{Study Areas}

The study areas were purposively selected covering 12 villages in the Taluk sub-district of Chainat Province in the middle region of Thailand (Figure 2). These areas were selected by Thailand's Department of Agricultural Extension based on published data on yields, costs and net income from rice plantations in 2005-2006, which were collected to avoid open-field burning in agricultural areas [24]. The main occupation of most people in the area is rice cultivation and it is an area that is suitable for growing rice according to the Agri-Map online platform that was jointly developed by the Ministry of Agriculture and Cooperatives, the Ministry of Science and Technology, and the National Electronics and Computer Technology Center as a member of the National Science and Technology Development Agency.

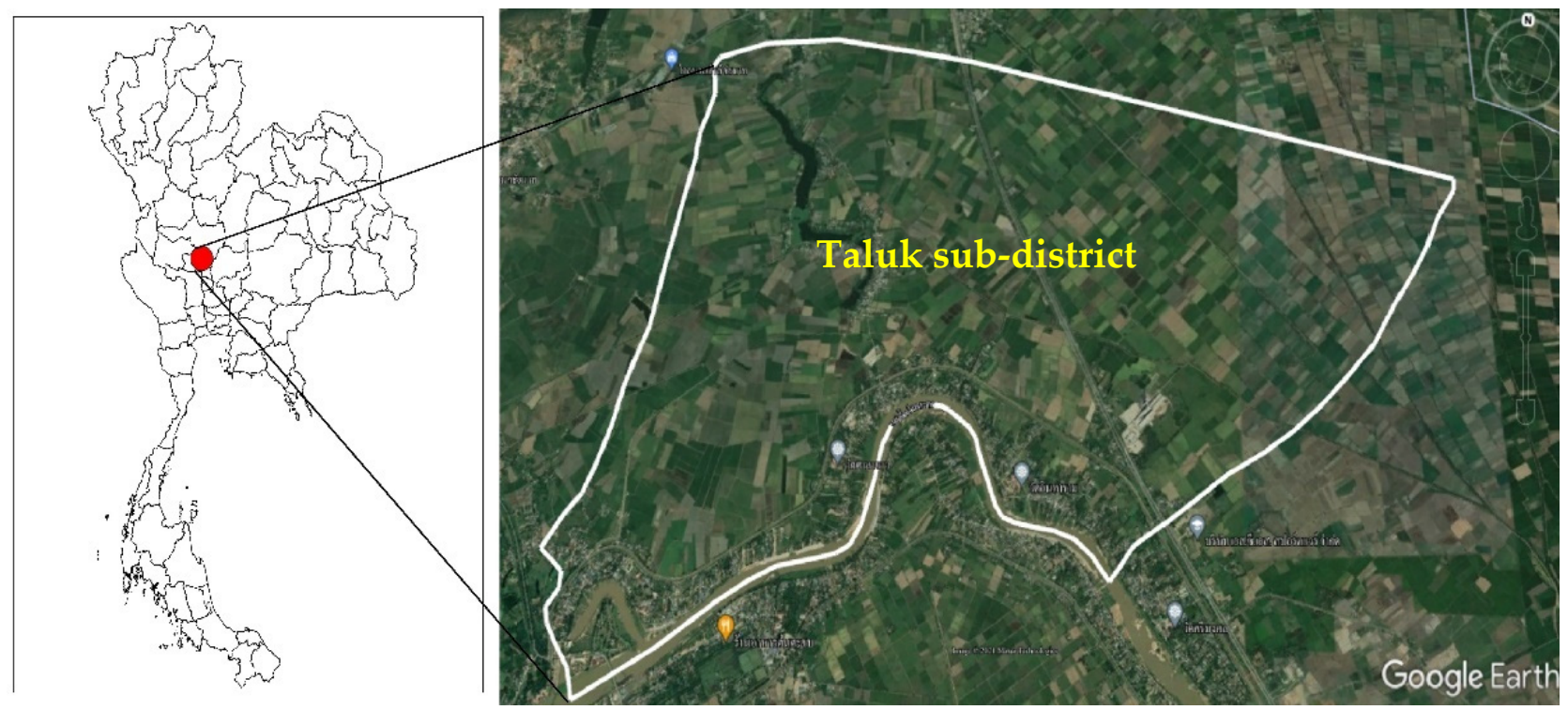

Figure 2. Study area.

\subsection{Sampling Design and Data Collection}

Farmers' household surveys were conducted by accidental or convenience sampling of farmers from 12 villages in the Taluk sub-district of Chainat Province, who were conveniently placed, willing to participate in answering the questionnaire and provide in-depth details. The researchers collected questionnaires from 240 local farmers via door-to-door visits and informal interviews to obtain details about their rice farming, and rice straw and stubble management.

The questionnaire was designed based on the TPB, VBN and HBM theories. The reliability of the questions regarding psychological factors was tested, with Cronbach's alpha being between 0.870 to 0.983 (Table 1 ). Consequently, the questions were deemed to be reliable and fit for the objectives of this study. 
Table 1. Psychological factors, variables, reliability test and reference theories.

\begin{tabular}{lccc}
\hline \multicolumn{1}{c}{ Psychological Factors } & Cronbach's Alpha & Reference Theories \\
\hline $\begin{array}{l}\text { (1) Perceived } \\
\text { pro-environmental personal } \\
\text { norms (PPN) }\end{array}$ & 0.983 & Value-Belief-Norm (VBN): Pro-environmental personal norms & [6,8] \\
\hline $\begin{array}{l}\text { (2) Perceived cues to rice } \\
\text { straw utilization (PCU) }\end{array}$ & 0.915 & Health Belief Model (HBM): Cues to action \\
\hline $\begin{array}{l}\text { (3) Perceived behavioral } \\
\text { control of rice straw } \\
\text { utilization (PBC) }\end{array}$ & 0.962 & Theory of planned behavior (TPB): Perceived behavioral control \\
\hline $\begin{array}{l}\text { (4) Perceived severity of rice } \\
\text { straw burning (PSB) }\end{array}$ & 0.941 & Health Belief Model (HBM): Perceived severity \\
\hline $\begin{array}{l}\text { (5) Perceived ascription of } \\
\text { responsibility (PAR) }\end{array}$ & 0.929 & Value-Belief-Norm (VBN): Ascription of responsibility \\
\hline $\begin{array}{l}\text { (6) Perceived benefits of rice } \\
\text { straw utilization (PBU) }\end{array}$ & 0.944 & Health Belief Model (HBM): perceived benefits \\
\hline $\begin{array}{l}\text { (7) Perceived benefits of } \\
\text { current option (PBO) }\end{array}$ & 0.870 & Health Belief Model (HBM): perceived benefits
\end{tabular}

To validate the questionnaire, three experts in different fields of agricultural management, environmental and health psychology, and environmental and health communication were invited individually in-person and online. The questionnaire was pre-tested with 10 farmers in the same province who were not be included in the final study. A few questions of the questionnaire were revised, alongside the language that was used based on the pilot farmers' suggestions that it be easier to understand by the farmers.

The questionnaire consisted of three main parts (Table 2): (1) demographic information; (2) rice straw and stubble management; and (3) psychological factors. A checklist, an open form and a five-point Likert scale were used to record their responses, where $1=$ minimum and $5=$ maximum scores.

\subsection{Data Analysis}

To understand farmers' perceptions regarding rice straw and stubble management including pro-environmental personal norms, the benefits of rice straw utilization, perceived behavioral control, ascription of responsibility, cues for rice straw utilization, severity of rice straw burning, and the benefits of the current option, cross-tabs and percentages were employed for data analysis. Moreover, stepwise multiple linear regression analysis was used to decode the psychological factors affecting farmers' rice straw and stubble management. The normal distribution test, a test of the homogeneity of variances, and a one-way ANOVA test using post hoc multiple comparisons (Scheffe) to compare the farmers' perceptions of rice straw and stubble management practices were also performed. These tests were analyzed using SPSS version 22.0.

The qualitative data from farmers' interviews were analyzed by thematic content analysis [25]. Firstly, recorded data was transcribed, read overall to familiarize the collected data, and classified into different issues based on the study objectives. Then, the QDA Miner Lite Program was employed to code, label the similar meaning, and group the data. The overall analysis from the Program was printed out and reviewed again. Then, the critical results were described by face-to-face discussions between two researchers according to the interview issues and study objectives. 
Table 2. The questions used in the questionnaire to ask respondents.

\begin{tabular}{|c|c|}
\hline Part & Questions \\
\hline $\begin{array}{l}\text { (1) Demographic information (a } \\
\text { checklist and an open form) }\end{array}$ & $\begin{array}{ll}1.1 & \text { Gender (1. male, } 2 . \text { female) } \\
1.2 & \text { Age (indicating years) } \\
1.3 & \text { Schooling (indicating years) } \\
1.4 & \text { Farmland owner (1. no, } 2 . \text { yes) } \\
1.5 & \text { Farm size (indicating areas: Rai) } \\
\text { 1.6 } & \text { Farming group attendance (1. no, } 2 . \text { yes) }\end{array}$ \\
\hline $\begin{array}{l}\text { (2) Rice straw and stubble management } \\
\text { (a checklist) }\end{array}$ & $\begin{array}{ll}2.1 & \text { Burning } \\
2.2 & \text { Compacting } \\
2.3 & \text { Incorporation } \\
2.4 & \text { Free-grazing ducks } \\
2.5 & \text { Mixed method } \\
\end{array}$ \\
\hline \multirow{7}{*}{$\begin{array}{l}\text { (3) Psychological factors (a five-point } \\
\text { Likert scale answer: } 5=\text { most, } 4=\text { more, } \\
3=\text { moderate, } 2=\text { low, } 1=\text { very low) }\end{array}$} & $\begin{array}{l}\text { 3.1 Perceived pro-environmental personal norms (PPN) } \\
\text { PPN1: The use of rice straw is consistent with your farming values. } \\
\text { PPN2: You feel it is your responsibility to help reduce air pollution. } \\
\text { PPN3: You feel guilty if you do not utilize the rice straw. }\end{array}$ \\
\hline & $\begin{array}{l}\text { 3.2 Perceived cues to rice straw utilization (PCU) } \\
\text { PCU1: You have read/heard/received the information about using rice straw to reduce environmental } \\
\text { problems. } \\
\text { PCU2: Local authorities educate about rice straw utilization. } \\
\text { PCU3: You can access facilities of rice straw utilization such as purchasing sites near the community. }\end{array}$ \\
\hline & $\begin{array}{l}\text { 3.3 Perceived behavioral control of rice straw utilization (PBC) } \\
\text { PBC1: You have a good understanding of how to gain benefits from rice straw. } \\
\text { PBC2: Rice straw utilization is easy and uncomplicated. } \\
\text { PBC3: You feel confident that rice straw can be utilized. }\end{array}$ \\
\hline & $\begin{array}{l}\text { 3.4 Perceived severity of rice straw burning (PSB) } \\
\text { PSB1: Rice straw burning is a threat to local people's health. } \\
\text { PSB2: Rice straw burning is a serious threat to the environment and agriculture. } \\
\text { PSB3: Rice straw burning is a serious threat for future generations. } \\
\text { PSB4: People and the environment cannot cope with the effects of rice straw burning. }\end{array}$ \\
\hline & $\begin{array}{l}\text { 3.5 Perceived ascription of responsibility (PAR) } \\
\text { PAR1: Everyone should be responsible for air pollution. } \\
\text { PAR2: People in the community should avoid activities that cause air pollution. }\end{array}$ \\
\hline & $\begin{array}{l}\text { 3.6 Perceived benefits of rice straw utilization (PBU) } \\
\text { PBU1: Rice straw utilization has a positive effect on agriculture and the environment around you. } \\
\text { PBU2: Rice straw utilization helps increase income. } \\
\text { PBU3: Rice straw utilization helps build good relationships in the community. } \\
\text { PBU4: Rice straw utilization does not incur an extra cost. } \\
\text { PBU5: Rice straw is more useful than burning, so it should be used for maximum benefit. }\end{array}$ \\
\hline & $\begin{array}{l}\text { 3.7 Perceived benefits of current option (PBO) } \\
\text { PBO1: Your rice straw and stubble management option can help generate income for yourself/your } \\
\text { family. } \\
\text { PBO2: Your rice straw and stubble management option has low costs. } \\
\text { PBO3: Your rice straw and stubble management option can help reduce air pollution. } \\
\text { PBO4: Your rice straw and stubble management option does not cause trouble for others and allows } \\
\text { people to coexist peacefully. } \\
\text { PBO5: Your rice straw and stubble management option is appropriate for the available resources in } \\
\text { your community. }\end{array}$ \\
\hline
\end{tabular}

\section{Results and Discussion}

\subsection{Demographic Information}

Most of the respondents were male (around 55.83\%). Their average ages, farm sizes, and levels of education were 51 years old, 19 Rais (3.04 hectares) and secondary school, respectively. Most farmers owned their rice farming area (91.67\%) but did not attend the farming group $(94.17 \%)$. Five main rice straw and stubble management practices were found in this area consisting of (1) burning $(43.75 \%)$, (2) compacting $(40.83 \%)$, (3) incorporation $(6.25 \%),(4)$ free-grazing ducks $(1.25 \%)$ and (5) mixed methods $(7.92 \%)$. The average costs and returns for each method of rice straw and stubble management are shown in Table 3. 
Table 3. Average costs and returns for each method of rice straw management.

\begin{tabular}{|c|c|c|}
\hline Rice Straw Management & Costs & Returns \\
\hline (1) burning & $\begin{array}{l}\text { Lighter } 10 \text { Baht/piece } \\
\text { (can use more than one time) }\end{array}$ & Fast straw management \\
\hline (2) compacting & - & $\begin{array}{l}\text { 120-180 Baht/rai or } \\
\text { 750-1125 Baht/hectare }\end{array}$ \\
\hline (3) incorporation & $\begin{array}{c}\text { Wage for plowing rice straw } \\
\text { (200 Baht/rai or } 1250 \text { Baht/hectare) }\end{array}$ & Soil nourishment \\
\hline (4) free-grazing ducks & $\begin{array}{c}\text { Water pumping } \\
\text { (75 Baht/rai or } 468.75 \text { Baht/hectare) }\end{array}$ & $\begin{array}{c}\text { Free duck eggs } \\
\text { (around } 30 \text { duck eggs) }\end{array}$ \\
\hline \multicolumn{3}{|l|}{ (5) mix method } \\
\hline - $\quad$ compacting & - & $\begin{array}{l}\text { 120-180 Baht/rai or } \\
\text { 750-1125 Baht/hectare }\end{array}$ \\
\hline - $\quad$ incorporation & $\begin{array}{c}\text { Water pumping } \\
\text { (75 Baht/rai or } 468.75 \text { Baht/hectare) }\end{array}$ & Soil nourishment \\
\hline - $\quad$ soil covering & - & Soil moisture \\
\hline
\end{tabular}

\subsection{Farmers' Rice Straw and Stubble Management and Their Perceptions}

Based on integrated quantitative and qualitative approaches, this study highlighted psychological factors that could reflect the farmers' demographic, social and economic factors as well. Five main rice straw and stubble management practices were found in the study area as described in detail below.

\subsubsection{Rice Straw Burning}

For the farmers who chose to burn rice straw, the lowest-rated perception was found for all sub-issues of PPN, PCU, PBC and PSB (Table S1).

For the perceived benefit of burning, cost-saving was found to be the highest-rated perception $(\mathrm{PBO} 2,69.52 \%)$, while generating income (PBO1, 85.71\%) and reducing air pollution (PBO3, 80.95\%) were the lowest-rated perceptions. The cost-saving from the burning method is in line with the findings of Ahmed et al. [26], who mentioned that rice straw utilization had higher costs than burning, so farmers in Pakistan adopted the burning method. This was also in line with the Malaysian farmers' perception of the ease and low cost of rice straw burning [27].

The lowest-rated perceptions regarding the utilization of rice straw were the fostering of good relationships (PBU3, 76.19\%) and the lack of additional cost requirements (PBU4, $85.71 \%$ ), which relate to the perceived benefits of rice straw utilization. This perception can hinder the adoption of rice straw utilization, as also supported by Launio et al. [1] who suggested that having a low income could prevent Filipino and Vietnamese farmers from adopting practices other than burning, as they were unwilling to pay more for rice straw and stubble management.

Moreover, a moderate-level perception rating (undecided) was found regarding the benefit for agriculture and the surrounding environment (PBU1, 80.95\%). Some of the farmers added that they were also interested in methods of rice straw utilization instead of burning, especially compacting, which was the method that generated the most interest provided that facilities could be supplied for them as well.

In light of the perceptions of farmers who were not sure about the advantages of using rice straw to benefit their agricultural activities and surrounding environment, and given the interest in rice straw compacting, the comparative communication highlighted each rice straw utilization method, as well as the costs and benefits for the agricultural system, environment and people. This was also supported by the findings of Rosmiza et al. [27], who suggested that farmers would be more active in participating in and adopting the use of a new technology if they could increase their profits. Moreover, to promote the 
adoption of rice straw utilization, Launio et al. [1] raised the importance of accessing appropriate public and private support by the farmers. Therefore, continuous agricultural advice by local authorities and agricultural extensionists should be arranged to promote confidence and the improvement of abilities relating to rice straw utilization instead of burning. Additionally, knowledge on the benefits of rice straw, which is rich in various substances and can be used as fertilizer, fodder, for bioenergy, etc. should be highlighted as well.

\subsubsection{Rice Straw Compacting}

The farmers who chose to compact rice straw perceived the benefit of this option at the highest level across all sub-elements, especially for generating income (PBO1, 100\%), reducing air pollution (PBO3, 100\%), and helping to live with others in the community peacefully (PBO4, 100\%), followed by saving costs for rice straw and stubble management $(\mathrm{PBO} 2,77.55 \%)$ and appropriateness for the available resources in the area (PBO5, 54.08\%) (Table S1). This highest-level perception rating was consistent with the perceived benefits of rice straw utilization as follows: most farmers strongly agree that rice straw is more useful than burning, so it should be used for maximum benefit (PBU5, 98.98\%) and the generation of income (PBU2, 92.86\%); secondly, most agree with the use of rice straw to benefit agriculture and the surrounding environment (PBU1, 100\%), that it helps to strengthen good relationships in the community (PBU3, 100\%) and has no additional costs (PBU4, 88.78\%).

Furthermore, the farmers gave high-level perception ratings regarding PPN and PBC. The utilization of rice straw has been a common practice for an average of $2-3$ years. Rice straw compacting is convenient and generates income for the farmers because the private sector that buys straw directly contacts the farmers at their paddy fields, and offers a price for rice straw, meaning that farmers can decide whether to sell the straw or not. Therefore, the farmers considered that, compared to methods of rice straw and stubble management such as burning, compacting is a new way that they see has advantages without disadvantages, so other farmers in their village should also choose this method. In addition, during the past $2-3$ years, there has been an issue of smog from open burning, therefore, compacting has been viewed as one solution that can help reduce air pollution. The farmers thought that everyone should take part in reducing air pollution as much as possible, and stated that they will continue to use this method if in the future the private sector still buys their rice straw.

It is interesting that the farmers perceived high (49.5\%) and moderate (47.3\%) levels of understanding for rice straw utilization, while perceived ease and confidence in rice straw utilization was at a high level (73.6\%), and some responded at the highest level (26.4\%). Consequently, the alternatives to rice straw utilization should be clearly communicated, both the methods/steps, as well as the costs and benefits to be earned by comparing each method. If these can be measured or compared in terms of money gained and lost, the clear alternatives to burning rice straw trend to be adopted by farmers.

The results of PAR showed that the farmers perceived at a high level the sub-issue that everyone should be responsible for air pollution (PAR1, 100\%). Meanwhile, they perceived at a moderate level that people in the community should avoid activities that might cause air pollution (PAR2, 61.22\%), because of an understanding of the necessity that some farmers need burning. They understood that some rice fields are not large enough for the private sector to directly contact and compact rice straw in their fields. In addition, most farmers rushed to maximize the amount of rice cultivation, so it is necessary to choose a rice straw and stubble management method that is fast, convenient, and does not cost a lot. The burning method fulfills these criteria compared with non-burning methods. Based on this reason, our survey resulted in a high-level perception rating $(100 \%$, not the highest level) regarding the issue that everyone should be responsible for air pollution.

PCU found that most farmers perceived the highest level of rice straw utilization facilities (PCU3, 57.1\%). There was a high level of perception for rice straw utilization 
education by local authorities (PCU2, 67\%) and a moderate level of perception for the reading/hearing/receiving of information expressing that utilizing rice straw reduces environmental problems (PCU1, 79.1\%). For rice straw compacting, a private sector representative made contact and agreed on the price of purchasing and the date of compacting rice straw in the paddy fields, so it was convenient to manage the rice straw. There were also local authorities to promote knowledge about rice straw utilization. Some of the farmers gained knowledge from attending community agricultural groups, especially largescale agriculture groups. However, most farmers do not have knowledge on how to gain the benefits of utilizing rice straw. Having agricultural agencies and academics promote knowledge and practice is, therefore, an important and effective way for farmers to learn how to gain benefits from rice straw. These findings reflect that farmers are more open to knowledge from local authorities than from other channels. Therefore, another viable approach may be to design communication streams through local authorities to directly promote rice straw utilization approaches and practical actions to farmers. Mechanisms to support rice straw utilization, which can be operated mainly by the farmers in the community should be also promoted.

Most farmers perceived the severity of rice straw burning at a moderate level. This was proven through the sub-issues that people and the environment were unable to cope with the effects of rice straw burning (PSB4, 91.0\%), followed by perceptions that burning straw poses a serious threat to the environment and agriculture (PSB2, 86.8\%), and that it poses a threat to community health (PSB1, 69.2\%). Most disagreed that rice straw burning was a serious threat for future generations (PSB3, 100\%).

The explanation provided by the farmers was that they did not feel rice straw burning was a very serious threat was because it did not cause a serious effect for a long time. Farmers only burnt the rice straw after harvesting and preparing for the next crop. In some years, rice could only be planted once or twice because of insufficient water for many crops. Each burning took a short period of time for the fire to be extinguished. Most farmers knew and understood their reasons for burning. At the same time, there were ways to protect themselves from the smog of burning, such as avoiding activities outside or in the open air, staying in the house, and keeping doors and windows closed. If they needed to be outside during the burning time, they also wore a mask to protect themselves from the burning smog.

\subsubsection{Rice Straw Incorporation}

Farmers who incorporated their rice straw perceived the highest benefits of rice straw utilization, i.e., that rice straw was more useful than burning, so it could be used for maximum benefit (PBU5, 100\%) (Table S1), which supported the finding of Connor, et al. [10]. The farmers realized the benefits of soil nourishment, which could reflect their high-level perception of the benefits of rice straw for agriculture and the surrounding environment (PBU1, 100\%). Furthermore, the farmers agreed that straw incorporation helped build good relationships in the community (PBU3, 100\%) and did not require additional costs (PBU4, $100 \%$ ), while the benefit of rice straw in terms of generating income (PBU2, 100\%) was perceived at a moderate level. This is because rice straw incorporation does not directly result in monetary return, but this is rather a byproduct that results from incorporation for soil nourishment.

These results were consistent with PPN, which had a high-level perception rating regarding farmers feeling guilty if rice straw was not utilized (PPN3, 100\%). Meanwhile, a moderate perception of rice straw utilization was consistent with farming values (PPN1, $100 \%$ ) and their responsibility to reduce air pollution (PPN2, 100\%). The crucial reasons for rice straw incorporation was lacking water resources to continue the next crop. So farmers let the rice straw dry naturally until enough water was available for the next crop of rice cultivation.

For farmers who had their own tractors, they incorporated rice straw and prepared for the next crop when water from the irrigation system was available. Most farmers did 
not think that rice straw incorporation would link to their responsibility for reducing air pollution, and they were mainly concerned about available resources in their area. Moreover, after gaining knowledge of the benefits of rice straw utilization from local authorities, agricultural academics and agricultural extensionists, they were more concerned about the benefits of rice straw in terms of soil nourishment, which would benefit rice growing in the future.

Regarding $\mathrm{PBC}$, most of the incorporation farmers reported a high level of perception that rice straw utilization was simple and uncomplicated $(\mathrm{PBC} 2,84.62 \%)$, and that rice straw was believed to be usable ( $\mathrm{PBC} 3,76.92 \%)$. Meanwhile, a moderate level of perception was expressed regarding how to use rice straw (PBC1, 61.54\%). It is still an issue that should be communicated, and greater understanding should be promoted to increase their self-efficacy regarding rice straw utilization. This was because the farmers were initially confident in the benefits of rice straw, and its perceived ease of use. Promoting knowledge that is clearly understandable could increase the occurrence of rice straw utilization.

The fact that everyone should be responsible for air pollution (PAR1, 100\%) was shown at a high level of perception for the ascription of responsibility, followed by a moderate perception that people in the community should avoid activities that cause air pollution (PAR2, 100\%). This group of farmers explained similar reasons for understanding the necessity of burning, as mentioned by compacting farmers.

Cues to rice straw utilization were highly perceived by the incorporation farmers for its facilities (PCU3, 61.5\%), while moderate perceptions were found for reducing environmental problems (PCU1, 100\%) and gaining knowledge from local authorities (PCU2, $76.9 \%$ ). Since possessing a tractor is an important aspect of rice straw incorporation, the farmers did not pay for the labor cost. They did not focus on acquiring knowledge by themselves or from local authorities, but they would attend training if it led to a direct benefit to themselves.

PSB was found at moderate to low perception levels. The ideas that people and the environment are unable to cope with the effects of rice straw burning (PSB4, 100\%), and that rice straw burning poses a serious threat to the environment and agriculture (PSB2, $86.8 \%$ ) were perceived at a moderate level, while rice straw burning being a serious threat for future generations (PSB3, 100\%) and a threat to community health (PSB1, 76.9\%) were perceived lower.

The incorporation farmers perceived the benefits of the current option at the highest levels for reducing air pollution (PBO3, 100\%), helping people in the community live together peacefully ( $\mathrm{PBO} 4,76.9 \%)$, and being suitable for the available resources in the area (PBO5, 53.85\%), these were followed by cost-saving (PBO2, 76.92\%), which was reported at a high level of perception.

On the contrary, a lower level of perception for generating income (PBO1, 100\%) was found. The farmers focused more on environmental benefits, especially to the soil in their paddy fields than on monetary benefit. This could benefit the surrounding environment and cause no problems for others due to a lack of burning. Rice straw incorporation mainly benefited their soil quality, so the lowest level of perception for this point was shown.

\subsubsection{Free-Grazing Ducks in the Paddy Field}

In terms of PBU, farmers who practiced free-grazing ducks in the paddy field had the highest level of perception that rice straw was more useful than burning it, so it should be used for maximum benefit (PBU5, 100\%). The high level of perception was shown for rice straw utilization having a positive effect on agriculture and the surrounding environment (PBU1, 100\%), helping build good relationships in the community (PBU3, 100\%) and not requiring additional costs (PBU4, 100\%). Meanwhile, a moderate perception was mentioned for gaining income (PBU2, 100\%) because the farmers did not earn a monetary return, but got duck eggs to eat that could reduce the cost of buying food (Table S1).

The results of perceived pro-environmental personal norms were found at a high level of perception for all sub-issues; rice straw utilization was in accordance with their farming 
values (PPN1, 100\%), their responsibility to reduce air pollution (PPN2, 100\%) and feeling guilty if rice straw was not utilized (PPN3, 100\%).

Having free-grazing ducks in the paddy field has been practiced for about 1-2 years because duck farmers have offered to raise ducks in the paddy fields after harvesting, and offered to give duck eggs in return. Moreover, this method was selected as the farmers realized the benefit of duck manure in their paddy field as a good fertilizer to nourish their soil. These are the main motivating reasons for the perception that this approach is consistent with their farming values.

In addition, the farmers had a high level of self-efficacy in rice straw utilization (PBC) on the issue of rice straw utilization being easy and uncomplicated (PBC2, 100\%), and they believed that rice straw could provide benefits ( $\mathrm{PBC} 3,100 \%)$ while having a moderate understanding of how to gain benefits from rice straw (PBC1, 100\%).

It is interesting that the results reflected the farmers' moderate knowledge and understanding of rice straw utilization, while the benefits of rice straw were the most recognized. Their recognition of its benefits should be employed as a key message of communication. Moreover, providing the clear steps of other methods on how to use rice straw for other benefits including mention of their costs and returns should be communicated, this could encourage farmers to consider alternative methods of rice straw utilization. This communication technique is called "action-knowledge" [28] and should be focused on relevance and usefulness, positive and negative examples, the suggestion of simple behaviors, the utilization of previous knowledge, fostering transferability, and providing information tailored for the specific context of action.

Ascription of responsibility of the incorporation farmers was reported at a high level of perception, i.e., that everyone should be responsible for air pollution (PAR1, 100\%), while a moderate level of perception that people in the community should avoid activities that cause air pollution (PAR2, 57.14\%) was noted. This is in line with the results concerning those farmers who chose other approaches to rice straw utilization (instead of burning), sharing similar reasons for understanding the necessity of burning by farmers. The farmers highlighted that everyone should help each other in any way they can to avoid activities that cause air pollution.

For the perception of cues to rice straw utilization, the majority of farmers employing free-grazing ducks in the paddy field expressed the highest perception of the straw utilization facilities (PCU3, 100\%), followed by a high level of rice straw utilization education by local authorities (PCU2, 100\%), and perceived reading/hearing/receiving knowledge that rice straw utilization reduces environmental problems (PCU1, 100\%) moderately, which is similar to those farmers who use rice straw for other purposes. The farmers added that there is a free-grazing ducks operator who contacted the farmers at their field to determine whether they were interested in raising ducks in the field, and who expressed that duck eggs would be given in return. In addition, this method is used during resting periods for their paddy fields, so they were not in a hurry to continue planting rice. The findings on this issue are in good agreement with results from compacting rice straw farmers, although they were more open to knowledge from local authorities than from other channels. The approach can be also applied to design communication through local authorities to directly provide knowledge to farmers.

A moderate perception was proved for PSB in that people and the environment cannot cope with the effects of rice straw burning (PSB4, 100\%), and that rice straw burning poses a serious threat to the environment and agriculture (PSB2, 100\%). A low perception was shown for the opinions that rice straw burning poses a threat to community health (PSB1, $100 \%$ ) and is a serious threat to future generations (PSB3, 100\%). It was notable that the perception levels of farmers who employed rice straw compacting and free-grazing ducks in the paddy field were similar and quite close to those who employed other approaches of rice straw utilization. Overall, the severity of the rice straw burning was not highly perceived by non-burning farmers due to an understanding of the necessity of burning for some farmers. 
A study on the PBO found that the farmers had the highest level of perception that using free-grazing ducks in the paddy field reduces air pollution (PBO3, 100\%). It was clear that this method did not require rice straw burning, which could help to reduce air pollution. Additionally, this method helped people in the community coexist peacefully (PBO4, 100\%) because of the lack of rice straw burning. Therefore, it did not affect others in the community and was suitable for the available resources in the area (PBO5, 100\%), such as not having enough water for the next crop. Cost-saving in rice straw and stubble management ( $\mathrm{PBO} 2,100 \%)$ was perceived at a moderate level for this approach because there is still a need to pump water into their paddy fields when the ducks are released. Meanwhile, a low perception of generating income (PBO1, 100\%) was expressed, because raising ducks in the paddy field did not provide a monetary return, but duck eggs were provided instead.

\subsubsection{Mixed Method}

The selected mixed-method consisted of compacting, incorporation and soil covering. Farmers employing this mixed-method for rice straw and stubble management preferred not to burn rice straw as the first priority, so they tried to employ as many alternatives as they could.

Farmers' perceptions of the use of the mixed method were found to be consistent among PPN and PBC for all sub-issues at a high level as follows: rice straw utilization was in line with their farming values (PPN1, 100\%); their responsibility to reduce air pollution (PPN2, 100\%); and feeling guilty for not using rice straw (PPN3, 85.71\%) (Table S1). The farmers stated that they realized the benefits of rice straw, so they tried to use it to benefit various purposes. Besides allowing the private sector to compact rice straw and incorporating rice straw into the soil, they owned orchards growing mango, banana and papaya, so they covered the soil with rice straw in order to increase moisture in the soil. They also realized that using rice straw reduced burning. Reducing rice straw burning as much as possible was considered to be part of a farmer's responsibility.

The farmers also believed that rice straw could be utilized ( $\mathrm{PBC} 3,85.71 \%)$, they stated their understanding of how to use rice straw $(\mathrm{PBC} 1,66.67 \%)$ and expressed the opinion that rice straw utilization was simple and uncomplicated (PBC2, 66.67\%). Most of the farmers participated in community farming groups, such as large-scale farming groups, which promoted more opportunities for training to enhance knowledge of rice straw utilization techniques. Some training also provided the opportunity to participate in practical activities and experiments, so they understood the process of implementing rice straw and felt that it was not too difficult to gain benefits from rice straw. Therefore, they have continued using rice straw to receive various benefits.

The results of PBU were in line with PBO, with the highest perception of rice straw being more useful than burning, so farmers thought it could be used for maximum benefit (PBU5, 90.48\%). A high level of perception was shown that rice straw had a beneficial effect on agriculture and the surrounding environment (PBU1, 100\%), increasing income (PBU2, $100 \%$ ), promoting good relationships in the community (PBU3, 100\%) and not requiring additional costs (PBU4, 95.24\%), which are congruent with the perceived benefits of their methods of rice straw and stubble management. Most of them reflected a high perception of rice straw compacting being useful for reducing air pollution (PBO3, 100\%), helping people in the community coexist peacefully (PBO4, 100\%) and being appropriate for the available resources in the area (PBO5, 85.71\%).

A high level of perception was mentioned for generating income (PBO1, 100\%) and cost-saving for rice straw and stubble management (PBO2, 100\%), with similar reasons being expressed as with compacting farmers. They realized the benefits of generating income first, then reducing air pollution was clearly a good result as well because rice straw was definitely not burned and resulted in peaceful coexistence in the community. The mixed-method chosen was suitable for their available resources because rice straw 
could also be used to cover the soil in their orchard to improve soil moisture. Overall, the mixed method did not incur expenses for rice straw utilization.

A study on the issue of the ascription of responsibility showed a high level of perception for all sub-issues, i.e., that everyone should be responsible for air pollution (PAR1, $100 \%$ ) and that people in the community should avoid activities that cause air pollution (PAR2, 57.14\%), which is in line with the perception of farmers employing other methods of rice straw utilization.

The results of the study on the issue of the perception of cues for rice straw utilization found that farmers who used rice straw to raise cows had a high perception of rice straw utilization facilities (PCU3, 80.95\%), followed by a moderate perception of education on rice straw utilization by local authorities (PCU2, 85.71\%), and of reading/hearing/receiving information that rice straw utilization reduced environmental problems (PCU1, 57.14\%).

PSB also showed similar results to other methods of rice straw utilization, at low to moderate levels. Most farmers perceived that rice straw burning poses a serious threat to the environment and agriculture (PSB2, 85.71\%) at a moderate level, alongside that it is a threat to community health (PSB1,57.14\%), and that people and the environment cannot cope with the effects of rice straw burning (PSB4, 100\%). Meanwhile, there was a low perception of rice straw burning as being a serious threat for future generations (PSB3, 100\%). The same level of perception of the PSB2, PSB3 and PSB4 issues were raised, which was slightly different only for PSB1, with similar reasons to those who were employing other methods of rice straw utilization being stated.

In conclusion (Table 4), the result of our study showed that the perceived benefits of current options for both burning and non-burning farmers played an important role in determining which practice was selected by the farmers, which was in line with the perceived benefits of PPE for influencing farmers' adoption of rice straw utilization techniques [7]. Similar to the results regarding perceived cues for practicing rice straw utilization techniques, access to facilities of rice straw utilization (PCU3) seemed to play an especially crucial role in the adoption of non-burning options.

However, the perceived severity of burning being at "disagree" to "undecided" levels did not really influence non-burning farmers' decisions, which was different from the finding of Abdollahzadeh and Sharifzadeh [7] who mentioned that perceived severity of the bad effects of pesticides influenced farmers' adoption of PPE.

The psychological factors based on HBM seemed to play a crucial role for non-burning farmers at the "strongly agree" and "agree" levels of perception. The role of HBM was consistent with Ataei et al. [8] who found it was a better predictor of intention than TPB.

PBC, as a part of TPB, was also mainly perceived by non-burning farmers as almost the highest level of perception, which was in quite good agreement with the results of Zhang et al. [6] regarding TPB prediction of self-interest-oriented behaviors.

Table 4. Summary of rice straw management options, influencing psychological factors and behavioural theories employed.

\begin{tabular}{|c|c|c|c|c|c|}
\hline Options & Strongly Disagree (1) & Disagree (2) & Undecided (3) & Agree (4) & Strongly Agree (5) \\
\hline Burning & $\begin{array}{c}\text { PPN (VBN); PBC (TPB); } \\
\text { PCU (HBM); PSB1,2,3 } \\
\text { (HBM); PBU3,4 (HBM); } \\
\text { PBO1,3 (HBM) }\end{array}$ & $\begin{array}{l}\text { PAR2 (VBN); PBU2,5 } \\
\text { (HBM); PSB4 (HBM) }\end{array}$ & $\begin{array}{l}\text { PAR1 (VBN); } \\
\text { PBU1 (HBM); } \\
\text { PBO4,5 (HBM) }\end{array}$ & PBO2 (HBM) & \\
\hline Non-burning & $\begin{array}{c}\text { PBO1 (incorporation) } \\
\text { (HBM) }\end{array}$ & $\begin{array}{c}\text { PBO1 (Free-grazing } \\
\text { ducks) (HBM); } \\
\text { PSB3 (HBM) } \\
\text { PSB1 (incorporation, } \\
\text { Free-grazing ducks) } \\
\text { (HBM) }\end{array}$ & $\begin{array}{c}\text { PBO2 (Free-grazing } \\
\text { ducks) (HBM) } \\
\text { PBU2 (Incorporation, } \\
\text { Free-grazing ducks) } \\
\text { (HBM) } \\
\text { PCU1 (HBM); PSB2,4 } \\
\text { (HBM); PSB1 } \\
\text { (compacting, mix) (HBM) }\end{array}$ & $\begin{array}{c}\text { PBO4,5 (Free-grazing } \\
\text { ducks) (HBM); } \\
\text { PBU1,3,4 (HBM) }\end{array}$ & $\begin{array}{c}\text { PBO3 (HBM); } \\
\text { PBO4,5 (compacting, } \\
\text { incorporation, mix) } \\
\text { (HBM) } \\
\text { PCU3 (HBM); } \\
\text { PBU5 (HBM); } \\
\text { PBU2 (compacting) } \\
\text { (HBM) }\end{array}$ \\
\hline & & \multicolumn{4}{|c|}{ PPN (VBN); PAR (VBN); PBC (TPB); PCU2 (HBM) } \\
\hline
\end{tabular}




\subsection{Decoding Rice Straw and Stubble Management Based on Farmers' Psychological Factors}

Rice straw and stubble management practices could reflect farmers' psychological perceptions, which were analyzed by stepwise multiple linear regression models (Table S1).

(1) Perceived pro-environmental personal norms (PPN)

The results clearly show that PPN was significantly negatively influenced by rice straw burning (PN1: $t=-67.553, p=0.000$; PN2: $t=-67.553, p=0.000$; PN3: $t=-48.848$, $p=0.000$ ). The results were also in line with the ANOVA of the burning approach with a significantly negative difference compared to non-burning approaches. These indicate that farmers adopting the burning method tended to have the lowest level of perception of PPN compared with non-burning approaches to rice straw and stubble management.

Farmers who chose to burn rice straw provided additional information that gaining benefits from rice straw was a method that they had never used before. The burning method has been employed for a long time, i.e., since the beginning of rice cultivation. Burning is therefore more in line with their farming values. Furthermore, they viewed that the responsibility to reduce air pollution would not be a matter of any one individual, but instead a communal responsibility.

Since not much damage is caused by burning, they did not feel that rice straw burning was a very serious threat. Burning is practiced for a short time of around $2 \mathrm{~h}$ and not frequently, only 1-3 times a year, it is practiced within the rice planting area only and does not spread to other areas. Surface fires were unlikely to cause much damage to the soil. The farmers also reflected that soil quality/properties have not yet been measured in some villages. Moreover, the negative effects of burning on the soil have not yet been shown. The farmers did not feel too guilty for choosing burning instead of rice straw utilization. Most people in the same community understood the reason for burning. When they noticed rice straw burning near their house, they stayed inside, closed windows and doors, and avoided being outside to protect their health.

Moreover, PPN1 and PPN2 were also significantly negatively influenced by farmers who employed rice straw incorporation (PPN1: $t=-7.165, p=0.000$; PPN2: $t=-7.165$, $p=0.000$ ). The results were consistent with the ANOVA of rice straw incorporation that showed a significantly negative difference when compared with other non-burning methods of rice straw compacting, free-grazing ducks and mixed methods. This result was supported by the farmers that do not rush for the next crop because of a lack of water from the irrigation system, so they chose to dry rice straw until enough water was available to start planting. In contrast, if there was enough water for growing rice, they would burn rice straw in order to continue planting the next crop. Consequently, the results of the stepwise regression found a significantly negative influence, but not a high value when compared to burning.

(2) Perceived cues to rice straw utilization (PCU)

Burning clearly negatively influenced PCU (PCU1: $t=-14.996, p=0.000$; PCU2: $t=-19.450, p=0.000$; PCU3: $t=-39.920, p=0.000$ ). Compacting also negatively influenced PCU1 $(t=-2.059, p=0.044)$, indicating that farmers did not seek much rice straw utilization knowledge on their own, similar to those employing burning. Meanwhile, the mixed method positively influenced PCU2 $(t=3.143, p=0.002)$. The results are also in line with the ANOVA of the burning approach showing a significantly negative difference compared to non-burning approaches.

The results showed that farmers who employed the burning method tended to have the lowest perception of all PCU components, while those who employed mixed methods more often realized the benefits of gaining knowledge about rice straw utilization from local authorities. This suggests that farmers who utilized mixed methods of rice straw and stubble management were part of an agricultural group, most likely a large-scale farming group. They could gain more knowledge on how to gain benefits from rice straw from local authorities and agricultural extensionists such as how incorporation could nourish their soil, and how covering the soil of orchards can maintain soil moisture. 
In order to promote a higher PCU perception in farmers selecting the burning approach, which can then encourage a higher perception of rice straw utilization, the communication of knowledge and practices with clear inclusion of practical action knowledge is a crucial point of communication. The perception of knowledge of rice straw utilization, which was still at a low level, should be promoted through various channels that are convenient for farmers to gain knowledge, particularly through social media, group gathering, training and workshops for sharing experiences.

(3) Perceived behavioral control of rice straw utilization (PBC)

PBC was highly negatively influenced by burning practice (PBC1: $t=-36.035$, $p=0.000$; PBC2: $t=-30.752, p=0.000$; PBC3: $t=-61.495, p=0.000$ ). The results were also essentially the same as the ANOVA of the burning approach, with a significantly negative difference compared with all non-burning approaches. This shows that burning farmers had the lowest perception of PBC, similar to the results of PPN and PCU, and the communication guidelines for burning farmers can be considered as discussed in the section on PPN and PCU above in order to promote all the factors together.

(4) Perceived severity of rice straw burning (PSB)

All sub-issues of PSB were highly negatively influenced by the burning practice (PSB1: $t=-28.227, p=0.000$; PSB2: $t=-45.599, p=0.000$; PSB3: $t=-28.342, p=0.000$ ). The results also confirmed the ANOVA of the burning approach with a significantly negative difference compared with non-burning approaches. As expected, farmers who selected rice straw burning had the lowest perception of PSB, which was one reason for their burning practice. This result also supports the finding of Rosmiza et al. [27], who revealed farmers' perception that rice straw burning did not cause a serious effect on their rice fields. This was also in good agreement with Connor et al. [10], who showed that when higher risks were perceived, there was less acceptance of the practice.

The insight explanation provided by the farmers was that burning rice straw was unlikely to have a significant impact on the people's health in the community. No one in the village had been diagnosed with respiratory disease. Burning was infrequent, which made them think that people and the environment could cope with the effects of burning. Some farmers further reflected that their burning was unlikely to cause the high dust levels that have been reported in northern Thailand during the summer season.

Farmers who employed rice straw incorporation and chose to feed ducks on their rice farm area stated that they did not feel that burning was a very serious danger and understood the reasons for choosing this method. The farmers only burnt their rice straw after harvesting and preparing for the next crop. In some years, rice could be planted only once or twice because of insufficient water for many cycles of farming. Most of the people in the community knew and understood each other. They could protect themselves from burning smoke by avoiding doing activities outside/in the open air, staying in the house, and keeping the doors and windows closed. If they needed to be outside during this period, they wore a mask which was also done to prevent COVID-19. The smoke did not continue for a long time, so the feeling of a non-serious threat was perceived.

(5) Perceived ascription of responsibility (PAR)

PAR was highly negatively influenced by burning (PAR1: $t=-35.078, p=0.000$; PAR2: $t=-27.237, p=0.000)$, while PAR2 $(t=-3.290, p=0.001)$ was also negatively influenced by incorporation. The results also agree with the ANOVA of the burning approach, showing a significantly negative difference compared with non-burning approaches.

The farmers who employed rice straw burning stated that local people in their community as a whole rarely did activities that clearly caused air pollution. Although the rice straw stubble was burned, it was not on a daily basis, and was considered unlikely to be a major contributor to air pollution. Overall, it was moderately agreed that everyone should be responsible for air pollution, not only the agricultural sector but also other sectors, such as the industrial and transportation sectors.

Those who employed rice straw incorporation reflected that their main reason to employ this method was due to a lack of water to continue rice growing. Therefore, they 
were not in a hurry to eliminate rice straw stubble. Some of them also realized the benefits of incorporation. That is why the stepwise regression of the incorporation method also negatively influenced PAR2.

(6) Perceived benefits of rice straw utilization (PBU)

The results clearly showed that the perceived benefits of rice straw utilization were significantly negatively influenced by rice straw burning for all elements (PBU1: $t=-35.078$, $p=0.000 ;$ PBU2: $t=-6.451, p=0.000$, PBU3: $t=-75.030, p=0.000 ;$ PBU4: $t=-67.290$, $p=0.000$; PBU5: $t=-70.586, p=0.000)$. Meanwhile, PBU2 was significantly positively influenced by rice straw compacting $(t=14.585, p=0.000)$ and the mixed method $(t=5.789$, $p=0.000)$.

Farmers who burned their rice straw reflected that, if rice straw was used, there would be an additional cost, but they were not clear on how much it costs. Some farmers stated that they had heard about rice straw for growing mushrooms, but this would incur a cost for preparing or cultivating. Moreover, they did not really know if it would be worth it or not.

In terms of utilizing rice straw to help strengthen community relationships, the farmers did not think that it would have much effect because burning did not cause conflict among the local people.

In terms of recognizing the benefits of rice straw, the farmers still did not know exactly how rice straw would be suitable for each purpose, and were not sure if it would be worth the cost of using rice straw or not. Conversely, the burning option was easy, convenient, and quickly provided a result as the next cycle of farming could be started immediately. Then, they would be able to earn money from rice production by selling to their customers or the market before other farmers. Therefore, a clear comparative message of rice straw utilization should be communicated by comparing the steps, costs and benefits of each method.

In addition, farmers who chose to burn were not convinced by rice straw utilization. They were not sure of the positive effect on agriculture and their surrounding environment. Therefore, it is important to communicate for better understanding and awareness, to visualize and realize the differences between rice straw burning and utilization. The benefits that could occur from rice straw utilization, in particular, need to be communicated and linked to benefits in terms of generating income for farmers. After that, benefits in terms of farmers' health, benefits for the environment, and for the society where they live should be highlighted.

The compacting farmers reflected that earning money from compacting was a key aspect motivating them to choose this option, and even more so as it generates income continuously. They realized the benefits of rice straw compacting as it required no investment, while it was also beneficial to agriculture and the environment because compacting rice straw could reduce burning. By obtaining knowledge from agricultural agencies and the village headman and publicizing this to the villagers through their local broadcasting tower and through the village meeting to avoid burning, farmers received information that burning in rice fields was a major cause of soil depletion causing their rice to grow poorly. The yield was lower than it should be and caused air pollution, which might cause a conflict between the farmers who burned and non-burning and non-farmer groups.

Farmers who employed mixed methods for rice straw and stubble management, including rice straw compacting, soil covering and incorporation, could also gain income from compacting. Moreover, using rice straw to cover their soil in orchards was another indirect way to generate income. Similar to the farmers employing rice straw incorporation, they thought that the practice was good for the soil in their rice fields. Additionally, they obtained knowledge from relevant agencies that promoted rice straw incorporation to increase soil nutrients. The farmers would feel guilty for not taking advantage of the rice straw to help nourish their soil. Most of the farmers who chose this method also owned a tractor for incorporation by themselves or by their family members, so they could save on the labor cost for incorporation. 
(7) Perceived benefits of current option (PBO)

The current method of rice straw and stubble management did not cause trouble for others, and allowed farmers to coexist peacefully (PBO4), but was highly negatively influenced by burning $(t=-54.455, p=0.000)$, followed by free-grazing ducks $(t=-5.795$, $p=0.000$ ). The results reflected that both groups of farmers perceived that their practices could make others feel uncomfortable due to the smog of burning, and annoyance from ducks in the area, which might cause some difficulties in terms of transportation and noise.

The perception of current options to generate income (PBO1) was highly positively influenced by compacting $(t=34.396, p=0.000)$ and mixed methods $(t=15.059, p=0.000)$, because both groups of farmers gained money from the private sector visiting their fields for rice straw compacting. The results also showed good congruence with PBU2 (rice straw utilization could generate income). These findings are also in accordance with Connor et al. [10], who mentioned that the benefit perceptions of rice straw management options can influence practice adoption.

Lower costs of the current practice (PBO2) were positively influenced by compacting $(t=10.281, p=0.000)$ and burning $(t=4.719, p=0.000)$, and negatively influenced by duck feeding $(t=-3.587, p=0.000)$. The negative result was in line with the reasons provided by the farmers employing rice straw for duck feed due to the cost of pumping water into the paddy field before feeding the ducks.

The current option to reduce air pollution (PBO3) was negatively influenced only by burning $(t=-93.247, p=0.000)$, proving that the farmers perceived that their practice could not help to reduce air pollution, but they maintained the practice because of being in a hurry to prepare for the next crop.

In terms of the current options being appropriate with resources in their area (PBO5), the results show that this was negatively influenced by burning $(t=-29.402, p=0.000)$ and free-grazing ducks $(t=-2.389, p=0.018)$, and positively influenced by mixed methods $(t=2.606, p=0.010)$.

Based on the perceived benefits of the current rice straw and stubble management methods, it was observed that farmers who burned rice straw realized the most benefit of burning in terms of cost reduction, while they had the least benefit in terms of generating income and reducing air pollution. Burning did not generate income, which was different from rice straw compacting, but it helped to earn money later because of the chance to start the next crop faster. Noticeably, an important factor was water resources, i.e., not having enough water from the irrigation system or rainwater could slow down the next crop.

In terms of reducing air pollution, it was noted by the farmers who chose to burn in comparison with non-burning farmers, that they perceived the lowest severity of rice straw burning. At the same time, they frankly stated that compared to non-burning methods, burning was still the least effective method to reduce air pollution. This is an interesting point showing that indeed the farmers were already aware of the negative effects of burning. Therefore, this is an opportunity to communicate alternative rice straw utilization methods and make these options widely accessible to farmers. Encouraging farmers to understand and obtain the benefits of non-burning methods may be possible such that in the future they will choose rice straw utilization instead of burning.

In addition, the farmers considered the burning method as appropriate for the resources available in their area, especially during the rainy season, as wet rice straw cannot be used for any purpose. Therefore, they realized that burning was the most appropriate method. In addition, due to the urgency of continuous farming according to the availability of water from the irrigation system, the farmers had to speed their farming to catch up with the water release period. Importantly, straw burning is the least time-consuming method of straw management. In addition, straw burning also helped to prevent rice pests when cultivating rice.

Compacting farmers emphasized that they selected this approach mainly due to the benefits of generating income. To reduce air pollution, it was clearly a good result, because rice straw was definitely not burned and the by-product was peaceful coexistence in the 
community. In addition, most were aware of rice straw utilization facilities due to the fact that in the process of compacting, the private sector came to their rice field and made an agreement on the price beforehand. The result is also consistent with the stepwise analysis that found positive effects on PBO1 and PBO2.

Moreover, based on the results of the ANOVA on rice straw compacting, a significantly positive difference compared to other non-burning methods was shown in terms of causing no trouble to others (PBO4), earning income (PBO1) and cost-saving (PBO2), particularly when compared with the incorporation and free-grazing duck methods. This implies (from the farmers' viewpoint) that rice straw compacting seems to be the best option of the non-burning rice straw and stubble management techniques. Therefore, the relevant stakeholders should take part in promoting and facilitating this option in order to promote self-efficacy and the adoption of this practice by farmers. At the same time, in-depth research and knowledge translation of each rice straw and stubble management option should be employed continuously to make farmers active, and to expose them to new knowledge and innovations in the management of rice straw and stubble.

\subsection{Communication Strategies to Promote Rice Straw Utilization for Achieving Sustainable Agriculture}

In this part, the integrated frameworks, namely the "social-ecological model", "the six domains of the full-spectrum approach" [29], the "sustainable agricultural social system" [30], the "environmental health literacy (EHL)" [31], the "agricultural knowledge and information system (AKIS)" [32] and personal ecological norms [28] were employed to develop communication strategies for promoting non-burning rice straw and stubble management to achieve social-ecological benefits for more sustainable agricultural production (Figure 3).

Within the community, there were both farmers attending groups and those farming individually. They had their own knowledge, attitude and skills on rice straw and stubble management. Communication can be both internal and external to their community, in which two-way communication, and communication oriented towards networking, should be promoted to enhance more confidence in rice straw utilization. Regarding levels of communication, intrapersonal communication was added from Greiner [29] as a starting point to design how to communicate, then it was connected to interpersonal and group communication, to mass media, and new web-based media; the techniques and tools to be used also need to be considered.

Supporting mechanisms can be generated from key stakeholders, i.e., (1) agricultural extensionists/local authorities, (2) central authorities, (3) researchers/academic sector and (4) private sector NGOs and media practitioners. The forms of support are (1) policy and regulations on climate-friendly agriculture, technology and investment for rice straw utilization, and (2) communication strategies. 
Agricultural extensionists/ local authorities

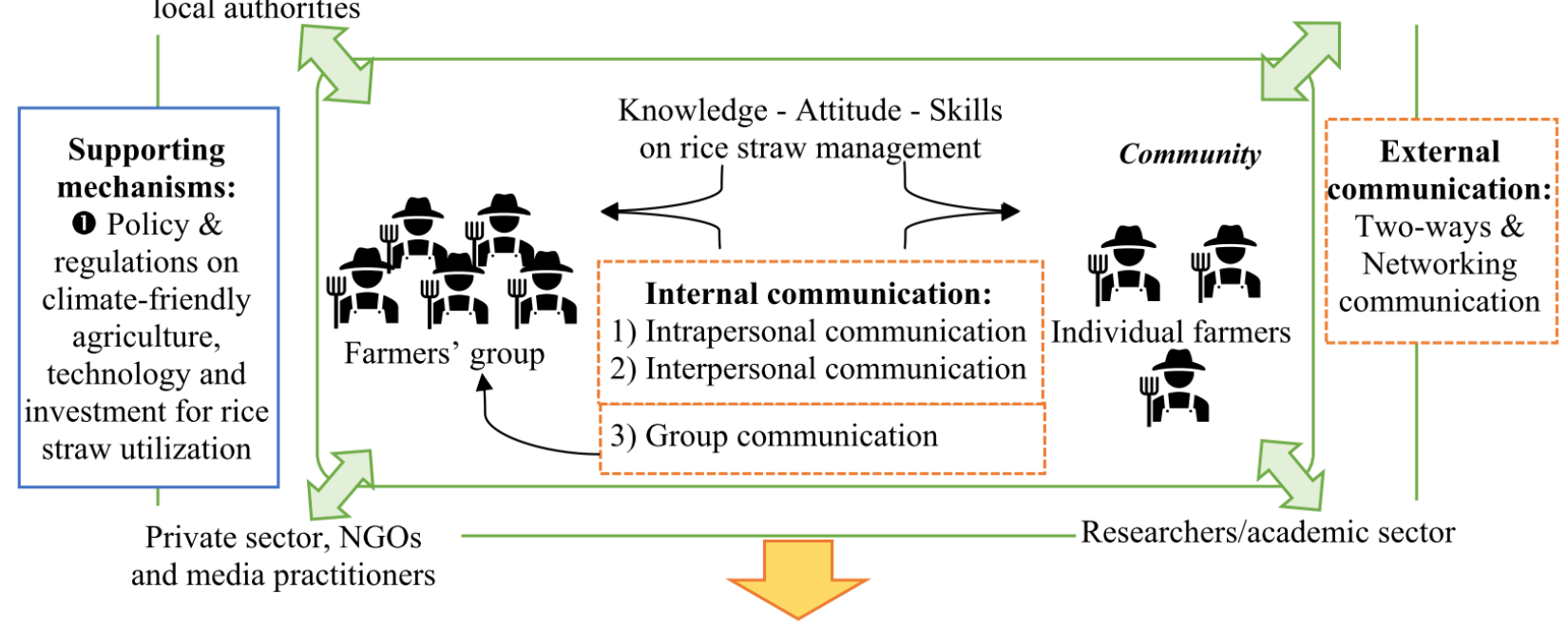

\begin{tabular}{|c|c|c|c|c|}
\hline $\begin{array}{r}\text { (1) Fa } \\
\text { ana }\end{array}$ & \multicolumn{3}{|c|}{ (2) Communication intervention } & $\begin{array}{l}\text { (3) Monitoring \& } \\
\text { Evaluation }\end{array}$ \\
\hline $\begin{array}{l}\text { Perceptions on: } \\
\text { - Pro- } \\
\text { environmental } \\
\text { personal norms } \\
\text { - Severity of rice }\end{array}$ & \multicolumn{2}{|c|}{$\begin{array}{l}\text { Messages selection (Rice straw utilization options) } \\
\text { - Methods/steps - Costs - Returns/benefits } \\
\text { - Comparison of each option }\end{array}$} & \multirow{4}{*}{$\begin{array}{l}\text { Channels selection } \\
\text { - Most accessible } \\
\text { and convenient } \\
\text { - Training } \\
\text { - workshop } \\
\text { - Short, clear and } \\
\text { concise } \\
\text { infographic } \\
\text { - Person media: } \\
\text { Trustworthy, } \\
\text { Hands-on } \\
\text { experience, } \\
\text { Continuous rice } \\
\text { straw utilization, } \\
\text { Communication } \\
\text { skills, Public mind }\end{array}$} & \begin{tabular}{|c} 
Research \& \\
development \\
(Critical \\
Participatory \\
Action Research; \\
C-PAR)
\end{tabular} \\
\hline $\begin{array}{l}\text { - Responsibility } \\
\text { - Behavioral } \\
\text { control } \\
\text { - Cues to rice } \\
\text { straw utilization }\end{array}$ & \multirow{3}{*}{$\begin{array}{l}\text { self-efficacy } \\
\text { - Relevance and } \\
\text { usefulness } \\
\text { - Positive and negative } \\
\text { examples } \\
\text { - Simple behaviors } \\
\text { - Pre-knowledge } \\
\text { linkage } \\
\text { - Practical knowledge } \\
\text { - Tailored information }\end{array}$} & \multirow{2}{*}{$\begin{array}{l}\text { perceived severity of rice } \\
\quad \text { straw burning } \\
\text { 1) Attention } \\
\text { 2) Involvement } \\
\text { 3) Comprehensive graphic } \\
\text { 4) Integrated strategies }\end{array}$} & & $\begin{array}{l}\text { Continuous } \\
\text { facilitation \& } \\
\text { feedback }\end{array}$ \\
\hline - Benefits of rice & & & & \\
\hline $\begin{array}{l}\text { - Benefits of the } \\
\text { current practices }\end{array}$ & & $\begin{array}{l}\text { perceived responsibility } \\
\text { 1) Self-awareness } \\
\text { 2) Self-commitment }\end{array}$ & & \\
\hline
\end{tabular}

\section{Sustainable agricultural production}

(income, relationship, healthy environment, healthy life)

Figure 3. Communication strategies for promoting non-burning rice straw and stubble management to achieve social-ecological benefits for more sustainable agricultural production.

Regarding communication strategies, farmers' perceptions should be analyzed and understood first, particularly their pro-environmental personal norms, and their perceptions of the severity of rice straw burning, responsibility, perceived behavioral control, cues for rice straw utilization, the benefits of rice straw utilization and the benefits of the current practices.

Next, the processes of communication intervention should highlight the selection of messages, message design and channel selection to fit with farmers. Rice straw utilization options should be selected as the key messages to promote non-burning rice straw and 
stubble management practices. Clear steps or methods, costs and benefits, and a comparison of each rice straw utilization option should be highlighted. The benefits to farmers, family members, people in the community and consumers should be emphasized, together with key messages regarding the potential these approaches have for increasing income, being healthy, peacefully coexisting with people in the community, and improving the better environment should be promoted to change behavior.

In order to promote more self-efficacy, the messages should highlight the relevance and usefulness of these techniques [33], positive and negative examples [33], simple behaviors [34], pre-knowledge linkage and practical knowledge, and tailored information [35]. Additionally, promoting action-knowledge and self-efficacy at the group level can help to achieve more effective non-burning rice straw management [36]. Moreover, collective efficacy as a group should be also considered, which can help to promote more effective rice straw utilization than self-efficacy [37]. Individual farmers might feel that only one person changing from burning to rice straw utilization would not be very meaningful to society. Therefore, group action tends to see clearer benefits or good results for both individuals and as a group or a community, so collective efficacy should be given as the initial priority as well.

Message design to promote perceived responsibility can focus on self-awareness and self-commitment. To enhance effective self-awareness, practical options and clear steps of practicing should be highlighted as key messages [28] in order to make it possible for farmers to adapt their burning to utilizing rice straw. This kind of message for communication can motivate farmers to adapt their current practice (burning) to incorporate new knowledge (rice straw utilization). Otherwise, a burning farmer might easily feel contradicted inside their mind because new information on rice straw utilization is irrelevant compared with their previous perceptions, knowledge and current practices of rice straw burning. When denying that rice straw utilization occurs, it is possible that farmers have less awareness of environmental concerns and values than of their survival.

To promote self-commitment, written, public and voluntary commitment seems to be more effective than spoken, private and involuntary commitment [38]. Commitment should also come together with the reasons for rice straw utilization to achieve more sustainable behavior [35].

Messages designed to highlight the perceived severity of rice straw burning can employ attention, involvement, comprehensive graphics and integrated strategies [28]. In order to expose and understand the impact of rice straw burning, this kind of knowledge and information should be interesting enough for the farmers to pay attention to, such as updated references and well-known metaphors, and analogies that are relevant in their society [34]. The more involvement and direct impacts there are to the farmers, the more possibility there will be for the farmers to concern themselves with environmental values, particularly referring to the institutions inside their villages and places they are familiar with [28]. Comprehensive and easy-to-understand graphics should be selected to disseminate facts on both the positive and negative points of rice straw burning and rice straw utilization, and farmers should be allowed to decide for themselves whether they trust the information and knowledge that is disseminated [34]. Moreover, integrated strategies should be employed such as linkages between knowledge dissemination and selfcommitment to create more possibilities to adopt rice straw utilization instead of burning; this strategy has succeeded before [39].

Communication channels that are the most accessible and convenient for farmers should be employed. Those using social media as a change agent should be trustworthy, should have taken action on rice straw utilization, should have seen the clear results of their practice, should have continued with methods of rice straw utilization, and should have communication skills to transfer knowledge and practices, as well as an outlook for passing on their practices as an example to fellow farmers. Thus, clear and concise online media and infographics focusing on how to gain benefits from rice straw should be also designed and distributed to farmers. Furthermore, farmers who still burn rice straw might 
not be interested in attending the training and workshops. Training and workshops should not take too much time (should not be more than three hours), and should try to provide a hands-on experience in order to demonstrate the practical success of rice straw utilization, which can influence farmers to change from burning to gain benefits from rice straw.

The last stage for communication strategies is monitoring and evaluation. Critical Participatory Action Research (C-PAR) should be applied as a practical framework for monitoring and evaluation, linking to continuous facilitation, feedback provision, and the creation of possibilities for farmers. C-PAR processes consist of practices and activities, including situation and context. The five main steps of C-PAR are as follows: (1) inspection of various operations, understanding and conditions under the intention of the participants; (2) critical questioning of participants' actions and outcomes; (3) applying communicative intervention to participants for an optional consensus conversation about the activities; (4) actions for behavior change, understanding the actions and conditions of the participants; and (5) evidence collection and monitoring of behavior change.

To ensure that farmers change their behavior from rice straw burning to rice straw utilization, support from local authorities should be also practiced, including monitoring and evaluating the perception, understanding the current practices of farmers. Any problems and limitations should be prioritized, brain-stormed, and discussed, and solutions proposed to support rice straw utilization should be easy and uncomplicated. After that, the farmers will be more aware of the benefits rather than feeling an additional burden, such as supporting the source of rice straw compacting service near the community, as well as contacting and coordinating the purchase of rice straw, which would be more convenient for farmers. Consultation from agricultural academics or extensionists and related parties should be performed to concretely and continuously facilitate rice straw utilization.

Furthermore, government agencies should take part in dealing with the problem as well. The overall communication management plan should be planned the national level under the issue of air pollution control, starting from related ministries such as the Pollution Control Department together with the Department of Agricultural Extension (Ministry of Agriculture), Department of Industrial Works (Ministry of Industry) and Department of Land Transportation (Ministry of Transport) to see results from the collaboration of all sectors. At the same time, this communication plan should be passed on to relevant local authorities, such as the agricultural sector, through provincial, district and sub-district agricultural offices.

\section{Conclusions and Recommendations}

The results clearly show that PPN, PCU, PBC, PSB, PAR and PBU were significantly negatively influenced by rice straw burning for all sub-elements, and were significantly negative compared to non-burning approaches. Meanwhile, PBO of burning farmers showed a significantly positive difference for cost-saving to manage rice straw and stubble when compared with the approaches of incorporation and free duck grazing. This indicates that farmers adopting the burning method tended to have the lowest perception of PPN, PCU, PBC, PSB, PAR and PBU compared with other non-burning approaches of rice straw and stubble management. In contrast, cost-saving together with rapid management seemed to be the key points for motivating farmers to retain their burning practice. The results for incorporation farmers also found a significantly negative influence on PPN1 and PPN2 because the main reason for this practice was insufficient water for the next crop, rather than concern about the benefits of incorporation. Therefore, the benefits of incorporation should be also highlighted as a key message for knowledge enhancement by agricultural extensionists and relevant authorities. Furthermore, farmers employing mixed methods of rice straw and stubble management significantly positively influenced PCU2, PBO1, PBU2 and PBO5. This group of farmers should be supported as key change agents to convey their hands-on experience in rice straw and stubble management to motivate burning farmers to open their minds to other methods besides burning. 
The integrated behavioral theories employed in this study proved that HBM, particularly the perceived benefits of current practice, seemed to play a crucial role for both burning and non-burning farmers. Moreover, perceived cues to practice, especially the accessing of facilities for rice straw utilization, seemed to play an important role in non-burning adoption. TPB, specifically PBC, appeared to be highly influenced by non-burning farmers.

To promote rice straw utilization and achieve sustainable agriculture, communication strategies should focus on message selection, message design and channel selection to fit with farmers. Key messages should focus on clear steps or methods, the costs and benefits of each rice straw utilization option, the benefits to farmers, their family members, people in the community and consumers, together with increasing income, being healthy, peacefully coexisting with people in the community, and an improved environment in order to promote the tendency to change behavior. Message design to promote action knowledge and self-efficacy at the group level, and to enhance perceived responsibility via self-awareness and self-commitment, can help to achieve more effective non-burning rice straw and stubble management.

Supplementary Materials: The following supporting information can be downloaded at: https:/ / www.mdpi.com/article/10.3390/agronomy12010200/s1, Table S1: Cross-tab and Stepwise multiple linear regression analysis.

Author Contributions: Conceptualization, S.S.; data curation, S.S.; formal analysis, S.S.; funding acquisition, S.S.; investigation, S.S.; methodology, S.S.; supervision, N.A.; writing一original draft, S.S.; writing-review \& editing, S.S and N.A. All authors have read and agreed to the published version of the manuscript.

Funding: This research project is supported by Mahidol University (Basic Research Fund: fiscal year 2021). We would also like to thank Thailand Science Research and Innovation (TSRI) for their funding to this project, contract number: BRF1-A8/2564.

Institutional Review Board Statement: The study was conducted according to the guidelines of the Declaration of Helsinki, and approved by the Institutional Review Board of Institute for Population and Social Research, Mahidol University (IPSR-IRB) (COA. No. 2021/01-003, date of approval: 28 January 2021).

Informed Consent Statement: Informed consent was obtained from all key informants involved in the study.

Data Availability Statement: Not applicable.

Acknowledgments: We express great thanks to all key informants for providing the information. We would also like to thank the anonymous reviewers for their comments and suggestions to improve this paper.

Conflicts of Interest: The authors declare no conflict of interest.

\section{References}

1. Launio, C.C.; Asis, C.A., Jr.; Manalili, R.G.; Javier, E.F.; Belizario, A.F. What factors influence choice of waste management practice? Evidence from rice straw management in the Philippines. Waste Manag. Res. 2014, 32, 140-148. [CrossRef]

2. Sereenonchai, S.; Arunrat, N.; Kamnoonwatana, D. Risk Perception on Haze Pollution and Willingness to Pay for Self-Protection and Haze Management in Chiang Mai Province, Northern Thailand. Atmosphere 2020, 11, 600. [CrossRef]

3. Arunrat, N.; Pumijumnong, N.; Sereenonchai, S. Air-Pollutant Emissions from Agricultural Burning in Mae Chaem Basin, Chiang Mai Province, Thailand. Atmosphere 2018, 9, 145. [CrossRef]

4. Office of Agricultural Economics. Agriculture Goes Forward with Campaign to Reduce Dust, Reduce Smoke, Inviting Farmers to Refrain from Burning in Agricultural Areas. 2020. Available online: https://www.oae.go.th/view/1/\%E0\%B8\%A3\%E0\%B8\%B2 \%E0\%B8\%A2\%E0\%B8\%A5\%E0\%B8\%B0\%E0\%B9\%80\%E0\%B8\%AD\%E0\%B8\%B5\%E0\%B8\%A2\%E0\%B8\%94\%E0\%B8\%82\%E0 \%B9\%88\%E0\%B8\%B2\%E0\%B8\%A7/\%E0\%B8\%82\%E0\%B9\%88\%E0\%B8\%B2\%E0\%B8\%A7\%20\%E0\%B8\%AA \%E0\%B8\%A8\%E0 \%B8\%81./33626/TH-TH (accessed on 20 November 2021). (In Thai)

5. Arunrat, N.; Wang, C.; Pumijumnong, N.; Sereenonchai, S.; Cai, W. Farmers' intention and decision to adapt to climate change: A case study in the Yom and Nan basins, Phichit province of Thailand. J. Clean. Prod. 2017, 143, 672-685. [CrossRef] 
6. Zhang, L.; Ruiz-Menjivar, J.; Luo, B.; Liang, Z.; Swisher, M.E. Predicting climate change mitigation and adaptation behaviors in agricultural production: A comparison of the theory of planned behavior and the Value-Belief-Norm Theory. J. Environ. Psychol. 2020, 68, 101408. [CrossRef]

7. Abdollahzadeh, G.; Sharifzadeh, M.S. Predicting farmers' intention to use PPE for prevent pesticide adverse effects: An examination of the Health Belief Model (HBM). J. Saudi Soc. Agric. Sci. 2021, 20, 40-47. [CrossRef]

8. Ataei, P.; Gholamrezai, S.; Movahedi, R.; Aliabadi, V. An analysis of farmers' intention to use green pesticides: The application of the extended theory of planned behavior and health belief model. J. Rural Stud. 2021, 81, 374-384. [CrossRef]

9. Guo, H.; Xu, S.; Wang, X.; Shu, W.; Chen, J.; Pan, C.; Guo, C. Driving Mechanism of Farmers' Utilization Behaviors of Straw Resources-An Empirical Study in Jilin Province, the Main Grain Producing Region in the Northeast Part of China. Sustainability 2021, 13, 2506. [CrossRef]

10. Connor, M.; Guia, A.H.D.; Quilloy, R.; Nguyen, H.V.; Gummert, M.; Sander, B.O. When climate change is not psychologically distant-Factors influencing the acceptance of sustainable farming practices in the Mekong river Delta of Vietnam. World Dev. Perspect. 2020, 18, 100204. [CrossRef]

11. Ajzen, I.; Fishbein, M. Understanding Attitudes and Predicting Social Behavior; Prentice-Hall: Englewood Cliffs, NJ, USA, 1980.

12. Fishbein, M.; Ajzen, I. Belief, Attitude, Intention and Behavior: An Introduction to Theory and Research; Addison-Wesley: Boston, MA, USA, 1975

13. Ajzen, I. From intentions to actions: A theory of planned behavior. In Action Control: From Cognition to Behavior; Kuhl, J., Beckmann J., Eds.; Springer: Berlin/Heidelberg, Germany, 1985.

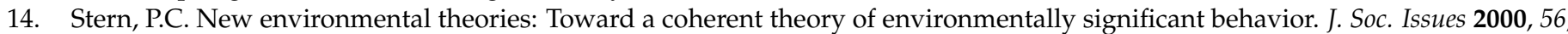
407-424. [CrossRef]

15. Glanz, K.; Rimer, B.K.; Viswanath, K. Health Behavior and Health Education: Theory, Research, and Practice; Jossey-Bass, John Wiley and Sons: San Francisco, CA, USA, 2008.

16. Bhandari, G.; Atreya, K.; Yang, X.; Fan, L.; Geissen, V. Factors affecting pesticide safety behaviour: The perceptions of Nepalese farmers and retailers. Sci. Total Environ. 2018, 631-632, 1560-1571. [CrossRef] [PubMed]

17. Yazdanpanah, M.; Tavakoli, K.; Marzban, A. Investigating factors that influenced framers' intention regarding safe use of pesticides through health belief model. Iran. Agric. Ext. Educ. J. 2016, 11, 21-29.

18. Lopes, A.A.; Viriyavipart, A.; Tasneem, D. The role of social influence in crop residue management: Evidence from Northern India. Ecol. Econ. 2020, 169, 106563. [CrossRef]

19. Kadam, K.L.; Forrest, L.H.; Jacobson, W.A. Rice straw as a lignocellulosic resource: Collection, processing, transportation, and environmental aspects. Biomass Bioenergy 2000, 18, 369-389. [CrossRef]

20. Mendoza, T. Enhancing crop residues recycling in the Philippine landscape. In Environmental Implications of Recycling and Recycled Products; Springer: Berlin/Heidelberg, Germany, 2015; pp. 79-100. [CrossRef]

21. Thanh, T.N.T. Comparative Assessment of Using Rice Straw for Rapid Composting and Straw Mushroom Production in Mitigating Greenhouse Gas Emissions in Mekong Delta Vietnam and Central Luzon, Philippines; University of the Philippines Los Baños: Laguna, Philippines, 2011.

22. Sun, D.; Ge, Y.; Zhou, Y. Punishing and rewarding: How do policy measures affect crop straw use by farmers? An empirical analysis of Jiangsu Province of China. Energy Policy 2019, 134, 110882. [CrossRef]

23. United Nations ESCAP. Reducing straw residue burning and air pollution through sustainable agricultural mechanization ESCAP/CED/2020/INF/4 2020. In Proceedings of the Economic and Social Commission for Asia and the Pacific Committee on Environment and Development, Bangkok, Thailand, 9-10 December 2020.

24. Department of Agriculture Extension. Stop Burning in Farmland. 2019. Available online: http:/ /www.royalagro.doae.go.th/ download/Bro_Burn.pdf (accessed on 20 November 2021). (In Thai)

25. Gray, D.E. Doing Research in the Real World, 4th ed.; SAGE Publications: Thousand Oaks, CA, USA, 2018.

26. Ahmed, T.; Ahmad, B.; Ahmad, W. Why do farmers burn rice residue? Examining farmers' choices in Punjab, Pakistan. Land Use Policy 2013, 47, 448-458. [CrossRef]

27. Rosmiza, M.Z.; Davies, W.P.; Rosniza, A.C.R.; Mazdi, M.; Jabil, M.J.; Wan, T.W.Y.; Che Rosmawati, C.M. Farmers' Participation in Rice Straw-Utilisation in the MADA Region of Kedah, Malaysia. Mediterr. J. Soc. Sci. 2014, 5, 23. [CrossRef]

28. Hamann, K.; Baumann, A.; Löschinger, D. Psychology of Environmental Protection-Handbook for Encouraging Sustainable Actions; Initiative Psychologie im Umweltschutz: Berlin, Germany, 2016. [CrossRef]

29. Greiner, K. The advantages and limits of a "full-spectrum" approach to communication for development (C4D). J. Dev. Commun. 2017, 28, 80-87.

30. Janker, J.; Mann, S.; Rist, S. Social sustainability in agriculture-A system-based framework. J. Rural Stud. 2019, 65, 32-42. [CrossRef]

31. Gray, K.M. From Content Knowledge to Community Change: A Review of Representations of Environmental Health Literacy. Int. J. Environ. Res. Public Health 2018, 15, 466. [CrossRef]

32. Demiryurek, K. Agricultural Knowledge and Innovation Systems and Social Communication Networks. In Agricultural Extension and Consultacy: Volume II Agricultural Extension and Consulting Methodology; Gaziosmanpaşa University Publication: Tokat, Turkey, 2014. 
33. Salas, E.; Tannenbaum, S.I.; Kraiger, K.; Smith-Jentsch, K.A. The science of training and development in organizations. What matters in practice. Psychol. Sci. Public Interest 2012, 13, 74-101. [CrossRef] [PubMed]

34. Gardner, G.T.; Stern, P.C. Environmental Problems and Human Behavior; Pearson Custom Publishing: Boston, MA, USA, 2002.

35. Lehman, P.K.; Geller, E.S. Behavioral analysis and environmental protection accomplishments and potential for more. Behav. Soc. Issues 2004, 13, 13-32. [CrossRef]

36. Barth, M.; Jugert, P.; Fritsche, I. Still underdetected-Social norms and collective efficacy predict the acceptance of electric vehicles in Germany. Transp. Res. Part F Traffic Psychol. Behav. 2016, 37, 64-77. [CrossRef]

37. Homburg, A.; Stolberg, A. Explaining pro-environmental behavior with a cognitive theory of stress. J. Environ. Psychol. 2006, 26, 1-14. [CrossRef]

38. Clayton, S.; Myers, G. Conservation Psychology: Understanding and Promoting Human Care for Nature; Wiley-Blackwell: West Sussex, UK, 2009.

39. Kazdin, A. Psychological science's contributions to a sustainable environment. Extending our reach to a grand challenge of society. Am. Psychol. 2009, 64, 339-356. [CrossRef] [PubMed] 